\title{
Machado de Assis
}

Representação e ironia em
"Teoria do medalhão" *

Edson Santos de Oliveira **

Resumo

Com base no conto "Teoria do Medalhão", de Machado de Assis, são dosenvolvidas aqui algumas reflexỏes sobre a ironia e a representaçāo, destacando-se, além de alguns elementos temáticos, a ironia enquanto processo de comunicação.

"É que a ironia prefere a política da simulaçâo de conformismo: se finge instalar-se em plena moral burguesa, é para desagregá-la com mais eficiência; se adota a política da maioria, é para melhor se proteger e garantir a sua batalha."

Lúcia Furtado de Mendonça Cyranka

- Trabalho apresentado na mesa redonda sobro "A ironia no conto de Machado de Assis", na Semana Comemorativa do Sesquicentenario de nascimento daquele escritor.

- Professor de Literalura Brasileira do COL TECIUFMG.

Doulorando em Literatura Comparada na Faculdado de Letras da UFMG. 
É comum na critica brasileira considerar a ironia em Machado de Assis como fruto da influênsia de escritores como Sterne e Swift. Haveria assim uma ironia-modelo, a européla, e uma ironla peritérica, copia daquela $\theta$ por isso mesmo inferior. É nessa trilha que se atém, por exemplo, Sivio Romero, alegando ser o humor em Machado, postiço, uma vez que ele não se sintoniza com o temperamento da nossa raça, tendo mais afinidade com o modo de ser germânico. 1

A falha da crlica tradicional fol ver a ironia como cópia, estruturada a nivel apenas de conteúdo, esquecendo-se de que ela é um processo de comunicaçăo, processo que supōe uma relaçăo dialógica entre o dito e o não-dito, o semelhante e o dilerente, precesso triádico, que implica numa relação de emissor, recetedor e pessoa-objeto. Ironia literária: mensagem enigma que desvenda, mascara e silencia signos, escapando ao controle de quem emite e de quem recebe o texto, contexto oscilante, signo em excesso, entrelugar descentrado abarcando a afirmaçăo e a negaçăo, a pergunta $\theta$ a resposta, inserindo-se nesse processo o leitor como narrador e o narrador como leitor.

Ignorando essa concepção da ironia como processo de linguagem, a crfica tradicional, estribada no biografismo, via também a obra de Machado como fruto de um ceticismo ácido enquanto reflexo de seu ressentimento mulato. Outras vezes louvava o seu humor, atendo-se apenas ao significado, ressaltando a análise psicológica, muitas vezes limitada e condicionada à vida pessoal do autor. Quando se prendiam ao nivel histórico, os estudos machadianos calam em uma relaçăo quase direta entre história e literatura. Existia, é claro, a consciência da sutileza da ficçăo machadiana, mas às vezes essa consciência era colocada entre parênteses em beneffcio da relaçăo simétrica vida/obra ou vida e momento histórico.

Ora, mais do que fotografar ou documentar a história, Machado de Assis, além de ter grande consciência da linguagem, irá ver essa realidade social sob a mira da ironia. Sua acentuada consciência histórica permitiu-the estabelecer esse distanciamento irônico em relação às inovaçbes européias que eram absorvidas pela colônia, como afírma Kátia Muricy:

Seu ceticismo em relação ao pensamento liberal e à racionalidade burguesa es o fitro crfico com que acolhe a entrada dos valores da modernidade européia no Brasil. O caminho fellz dessa crlica passou muitas vezes pala ironia ds inovapoes da medicina. Passagem inevitável já que a medicina fol, entre nós, o velculo da modemização.2

Tomando como ponto de partida a relação ironia e representação, tentarei mostrar como a ideologia naturalista do século XIX, calcada na simetria planejada, preserva o jogo da representaçăo social, o mesmo ocorrendo com o comportamento ambiguo da ciência e da polfica. Tudo isso nada mais faz do que preservar um saber codificado, transmitido de pai para filho a fim de manter o discurso maqulavélico do poder. Finalmente, na última parte do trabalho, espero demonstrar como a representaçăo social se associa ao código verbal, na medida em que a linguagem, por sua natureza mesma de representação, acaba sendo instrumento de ostentaçăo para se atingir o poder. É o que espero de- 
senvolver neste trabalho, tentando desvendar os bastidores da escrita irônica machadiana no conto "Teoria do Medalhão"3.

\section{I - A representação social}

A imagem do medalhão não se restringe a esse conto que vai ser analisado. Ela perpassa por toda a escrita machadiana. É o que afirma Dirce Côrtes Riedel:

O medalhão é uma metafora-programa que se concretiza no comportamento da maioria dos personagens machadianos que alcançam prestígio social, levantando-se acima da obscuridade comume firmando-se como ornamento indispensável da sociedade. 4

Como medalhão agiu Palha ao usar estrategicamente a mulher Sofia diante da ingênua cobiça de Rubião. Brás Cubas quis ser medalhão ao sonhar ter inventado o famoso emplastro anti-hipocondriaco, como afirma no inicio do romancé: "Assim, a minha idéia trazia duas faces como as medalhas, uma virada para o público, outra para mim. De um lado, filantropia e lucro; de outro lado, sede de nomeada. Digamos: - amor da gloria"5.

Medalhóes são alguns personagens femininos de Machado (Capitu, Sofia, Virglia e outros) que sabem dissimular por instinto, oscilando entre um comportamento individual e uma máscara social ostentada.

Representar se torna assim um jogo entre o ser e o parecer, uma oscilação entre o que se é na realidade e o que se aparenta ser no convivio social, resultando num recurso irônico usado pelo autor-implicito que apresenta o processo, mas não se identifica com ele, preferindo os bastidores à cena. É como afirma Lúcia Furtado:

É proprio da ironia o tema da máscara ou do teatro, melos de que se utiliza o autor, para colocar-se dentro do jogo, sem se confundir com ele, o que the permite, ao mesmo tempo, a reffexão e a isenção de espirito. 6

Na ironia literária, como no teatro, a mensagem oscila entre o dito e o näodito. $O$ discurso manifesto e o latente acabam por fundir-se e, paradoxalmente, a eficiência do texto velado só se dá diante da máscara do texto desvelado7. É nessa linha que se estabelece a ironia em Machado, isto é, ela se manifesta dialeticamente na apresentação dos personagens e no distanciamento crftico do autor-impilcito em relação a eles. Há assim um emissor (o autor-implicito), a pessoa-objeto (os personagens que representam) e finalmente o recebedor (o leitor) que percebe a ruptura irónica, caso tenha competéncia suficiente para decodificá-la8.

Afirma Jankélévitch que a litote é a formalização acabada da ironia, isso porque o ironista prefere recuar, mostrando sıtuações ao invés de interferir nelas diretamente9. O discurso irônico se torna, desse modo, mais eficiente à proporção que renuncia estrategicamente aos sinais irônicos, deixando que 
eles se entremostrem. Essa omissão do emissor, que de vez em quando se deixa entrever, poderia ser comparada à falta na psicanálise: o desejo do autor-implicito aceila se deixar faltar e sutilmente se inscreve, metonimicamente, nas teias do texto dos personagens.

O autor-implicito se posiciona assim dialeticamente entre o silencio e a fala dos personagens, deixando, na maioria das vezes, que eles se percam nas malhas do seu próprio discurso. E a ironia se instaura, paradoxalmente, pelo silencio, na medida, em que o que fol pressuposto acaba tendo mais efeito do que o que foi dito. A ironia se torna entåo diretamente proporcional ao vazio da fala dos personagens. A uma toquacidade comprometedora deles se articula sabiamente um silêncio cético do autor-implicito, configurando o discurso irônico e estreitando os laços de solidariedade entre o emissor e o leltor, ao mesmo tempo que se acentua uma ruplura entre o primeiro e os personagens apresentados. Como afirma Maria de Lourdes Ferraz:

Ora $\dot{\theta}$ a intença do narrador que sobressai, ora é a funçåo de vi tima da mensagem que é posta em realce, ora é a percepça que o destinatário tem da mensagem ou da intençáo do narrador que resume o efeito irónico. 10

A ironia machadiana, na esteira da representação, se articula assim a nivel social e a nivel da linguagem. No primeiro caso através dos recursos sociais ensinados de pai para filho a fim de que o filho consiga o poder. No segundo caso através da posição do autor-implicito que recua estrategicamente, permitindo que os personagens se manifestem, solidarizando-se com o recebedor e corroendo o discurso da pessoa-objeto da ironia. Um exemplo do conto esclarece bem esse processo: ao aconselhar o filho, o pai lhe receila o jogo. A ironia então se manilesta quando ele the diz que os jogos recomendáveis são o domino, o uiste $\theta$ o voltarete, justamente jogos praticados individualmente, que não pedem a participação de uma platéia, alvo dos interesses do candidato a medalhão. Além disso, esses jogos lazem descansar o cérebro restituindo ao praticante novas forças para que use com majs acuidade a inteligência, o que seria um perigo para quem quer ser medalhão.

Se representar é metáfora de jogar, evidentemente essa arte não necessita de um minimo esforço mental, nascendo com a vivência e a observaçāo, sem ser necessária uma escolaridade delerminada. Não é sem razão que a mulher, que normalmente não tinha instruçåo, $\theta$ apresentada por Machado como um ser capaz de dissimular: Capitu, Virgllia, Sofla representam com naturalidade o jogo social, oscilando contraditoriamente na manutenção do decoro e na sedução de aparência. Uma vez que a representação näo implica em capacidade de rélexăo, percebe-se claramente a ironia do autor-implicito na medida em que 0 ato de representar é enfocado como a "ciencia de pensar o pensado".

De um lado, o pai com o seu excesso de racionalismo burguês e persuasão patriarcal: de outro, a atitude ingênua do filho que beira à puerilidade. É dessa instabilidade, dessa situaçåo paradoxal entre a razão $\theta$ a ingenuidade. que se dá o diálogo no conto, diálogo que, sob a mira irônica do autor-implícito, é encarado como "coisa importante" que tem de ser realizada a portas fechadas para resguardar a hipocrisia burguesa, diálogo de pessoas "maiores de 
idade", "com mais de vinte e um anos completos": "Fecha aquela porta: vou dfzer-te coisas importantes." (p. 101). Dada a hilaridade do filho, o diálogo acaba, paradoxalmente, se tornando um monólogo. E a ironia da cena chega ao cllmax no final do conto, quando o pai compara a conversa à obra de Maquiavel: "Guardadas as proporçðes, a conversa desta noite vale o principe de Machiavelli. Vamos dormir." (p. 115)

A comparaçáo do diálogo à obra de Maquiavel, na ótica do autor-implicito, soa como uma caricatura social, já que o pai é apresentado como o representante típico de uma classe burguesa de um pals provinciano, ansioso por se europeizar, tentando se mirar romanticamente no comportamento da nobrezá européia. E esse desejo de enobrecer da burguesia năo passa de uma busca de ascensăo. Para se chegar ao poder é preciso tomar verossimil uma realidade distante num contexto social provinciano. Enobrecer, criar situaçős semeIhantes às da Europa em um ambiente semi-urbanizado era uma necessidade de adquirir favores do Estado, como afirma Kátia Muricy: "Para as elites brasileiras, enobrecer-se era um imperativo. Questáo de poderio polfico e economico, a introduçáo na aristocracia abria-the a máquina dos privilégios do Estado."11

Esse desejo de enobrecer corresponde a um sentimento de localismo inforior da colönia diante dos valores das metrópoles, colocados como universais. Recentemente Roberto Schwarz, em um estudo sobre Machado de Assis, vê a essência do esplrito machadiano como fruto dessa dialética entre o local e o universal:

Noutras palavras, em nossa hipotese a brasilidade de Machado náo reside em seu extraordinário trabalho de notação local, de que naturalmente depende, nem é anulada pelo discurso universalista, que é um estrato importante de sua literatura. Essas duas dimensóes, que sấo dados palpáveis, compóem-se (com mais outras) em fórmulas e formas que as relativizam, de que sấo a matéria dissonante, e que, elas sim, traduzem o sentimento intimo de seu tempo e país a que Machado se refere. 12

Acredito que essa essência Intima da obra machadiana a que se refere Roberto Schwarz (essa oscilação dialética entre o local e o universal) se deve bastante à estruturação do discurso irônico, que dissolve e relativiza os valores tanto universais como locais.

No conto "Teoria do Medalhăo", ao moldar o filho, o pai nada mais faz do que despertá-lo e conscientizá-lo da importância de se enobrecer, tentando forjar a sua personalidade: medalhåo frustrado que $\hat{e}, 0$ pai quer inculcar em seu herdeiro uma outra maneira de ser, moldando nele o medalhão que não foi. Năo é sem razăo que, ironicamente, o diálogo se dá num espaço fechado, à noite, na hora de dormir, a fim de que o filho rumine bem o que foi dito: "Vamos dormir, que é larde, rumina bem o que te disse, meu filho" (p. 115, grifo meu).

Ruminar nessa frase é um verbo sintomálico e implica em animalizar a personalidade, provando estar a ciência a serviço da polficica. É interessante ver agora, mais detalhadamente, como se dá essa relação e como se estabelece o "corte" irônico de Machado em relaçāo à estética do Naturalismo. 


\section{Tal pai, tal filho}

A ideologia do Naturalismo, no Brasil da segunda metade do século XIX, impôs um saber cientfico aliado a um poder polftico. $O$ discurso literário naturalista será assim um discurso da simetria, tendo como representante típico desse saber a figura do médico, que terá uma forte influência na conduta individual e social. Cabe a ele zelar pela higiene familiar, pela boa conduta moral da famtlia, estribado que estava no conhecimento das leis das ciências biológicas. A literatura naturalista será, dessa forma, a divulgadora das leis fisiológicas através dos seus romances ${ }^{10}$.

Em Machado de Assis, a ironia ao saber médico está presente principatmente no conto "O Alienista". Simåo Bacamarte é o protótipo do cientista racional que tudo pode e a todos manipula com a sua obsessảo pelos desequillbrios mentais e pelas leis hereditárias. Na escolha da esposa, por exemplo, ele nåo leva em conta a beleza fisica, mas a saúde do corpo de Dona Evarista na vä expectativa de ter descendentes vigorosos. Mas a ironia mais ferina se dá quando o Dr. Bacamarte torma um pacto com o barbeiro, lider da rebeliąo: ciência e polticica al se dão as mãos nos rumos da administração de ltagual.

O médico é, como se vê, o detentor das leis genéticas, aquele que zela pela saúde social, pai metalórico que cuida da descendéncia genulna. $O$ discurso naturalista será assim o discurso da continuldade heredítária. Sob a custódia das ciências biológicas, o ditado "Tal pai, tal filho" se adapta perfeitamente à sociedade da época. $E$ o pal a garantia da raça $\theta$ consequentemente do património. A ele cabe administrar os negócios da famnlia, ele era o poder supremo, podendo fazer justiça com as próprias mãos, como afirma Kátia Muricy:

Do pai também era a iniciativa económica e poitica. A prova dessa onipoténcia paterna $e$ encontrada, em alguns extremos, no proferimento de sentenças contra os descendentes rebeldes, assim como no julgamento de sous agregados e adversários, sem se dirigir à justiça real. 14

O pai é aquele que detém o poder e o respeito. A sua autoridade implica em um saber que, se não for erudito, é pelo menos um saber de experiência, saber que estava reiterado pela continuidade hereditária da ideologia naturalista. $O$ pai, no conto de Machado, se arvora assim na delesa das simetrias hereditárias, econômicas e pollticas. Daf tentar fazer do filho um medalhăo perfeito com medo de que ele não corresponda às expectativas paternas. Não há outro caminho para o filho nessa ideologia burguesa: ou o filho excede o pai ou é, no minimo, igual a ele. Por trás dessa homologia, dessa excessiva prudéncia, a figura do filho, como possivel medalhão derrotado, $\theta$ um constante fantasma $\theta$ uma ameaça à ordem vigente. É dessa desarticulação virtual (mas não real) entre pai e filho que se tece a ironia do texto, já que o bom senso burguês espera que haja uma analogia ou um aperfeiçoamento da descendência familiar, analogia que se estende à unidade nacional, à ordem patriarcal, tudo isso sob a égide da ciência biológica. 
Em "Teoria do Medalháo", o distanciamento irônico se dá exatamente na medida em que a equação "Tal pai, tal filho" 6 substitufda por um latente "Tal pai, qual filho?", através de um esforço descomunal por parte do paj para que seu filho não o frustre na carreira de medalhão, já que o genitor não conseguiu realizar seu intento. Na sua ingenuidade também descomunal, o filho se coloca como uma interrogaçāo, nảo havendo na narrativa nenhuma garantia dele exceder o pai. Por um lado, há uma forte capacidade de persuasão paterna, construlda grotescamente sobre o comportamento social de farsa e representaçăo. Por outro lado, nos bastidores, o autor-implicito relativiza tanto as convicçóes paternas quanto a ingenuidade do filho, irunizando a cena.

\section{A amblgüldade da ciência e da política}

Como foi visto anteriormente, o desejo de elitização, como forma de garantir os privilégios do Estado, se dava através da polficica, que estava de mãos dadas com o saber cientfico. Tentando dominar ideologicamente, as elites brasileiras vão assumir muilas vezes um comportamento amblguo, oscilando entre as teorias cientficas progressistas da Europa e o compromisso conservador com a ordem patriarcal. Esse comportamento dúbio das elites se reffete nas reaçōes do medalhảo, já que a representação social e a capacidade de simulaçáo dele o obrigava a ser ao mesmo tempo conservador e progressista:

- Vejo por al que vosmecé condena toda e qualquer aplicaçáo de processos modernos. (p. 108)

- Entendemo-nos. Condeno a aplicaçảo, louvo a denominaçáo.

Por trás de um discurso cientfico tido como progressista, o pai "louva a denominaçâo", mas na prática é conservador e "condena a aplicação". É nessa mesma linha irónica de desarticulaçáo entre teoria e prática que o tfulo do conto - "Teoria do Medalhão" - pretende ser um conjunto de normas empíricas para se comportar politicamente. Além do tilulo, há outras marcaçőes irônicas: a referência ao Tratado cientffico da criaçáo de carneiros acena duplamente para a teoria cientffica, ao mesmo tempo que aponta para a atitude pragmática do poItico, que mata um carneiro para arrebanhar adeptos. Uma outra ironia à ciencia se dá através da expressão "estatísticas escrupulosas" aplicada aos jogadores de bilhar, salientando a inutilidade das expresszes cientfficas diante de uma situação lúdica, como é o caso do jogo em questão.

A ironia machadiana pőe, assim, sob a sua mira, a polfica e a ciência biologica, ambas empenhadas na concepção burguesa da vida como loteria:

A vida, Janjão, é uma enorme toteria: os prémios são poucos, os malogrados inúmeros, e com os suspiros de uma geraçáo é que se amassam as esperanças do outra. (p. 102)

Esses "suspiros de uma geraçáo que amassam as esperanças de outra" năo passam de um espelhamento da clássica expressão machadiana de Quin. 
cas Borba - "Ao vencedor as batatas" - que ironizava o evolucionismo da época. No fundo, o que há é a lei da compensação: assim como uma tribo tem de morrer para que a outra viva, do mesmo modo é necessário que haja frustraçöes do pai para que se ergam os sonhos dos filhos, comportamento típico da ideologia "clentifica" da época e que também pode ser aplicado à polftica: não importa que os anseios de uma geraçåo sejam amassados, desde que os sonhos da geraçåo seguinte se realizem, sintese perfeita da teoria maquiavélica do poder. Dá a referência ao pensador pragmático por excelência: Nicolau Maquiavel.

\section{O discurso maquiavélico do poder}

A referência feita a Maquiavel soa evidentemente como irônica, mas há uma certa sintonia entre o texto polltico do pensador florentino e o conto machadiano.

Primeiramente importa salientar que $O$ Principe es estruturado virtualmente como um diálogo, já que se percebe nos bastidores do texto "uma voz da experiência polftica" que aconselha o futuro governante. O mesmo ocorre no texto de Machado: existe uma experiencia paterna que aconselhe o filho, a fim de que ele, ironicamente, metaforizado em príncipe europeu, de forma distanciada, mordaz, pelo autor-implicito, náo frustre as expectativas do pai.

No que se refere á experiência, convém ressaltar a pecualiaridade da obra de Maquiavel, que fará um corte em relaçáo aos outros tratados de poltitica anteriores. Enquanto outros teóricos politicos se prendiam à especulação filosófica, como acontece com Platão, Aristóteles ou Erasmo de Rotterdan, esse último contemporâneo de Maquiavel, $O$ Príncipe se prenderá a uma investigação empfrica, que não se constrói na mera vivência pessoal, mas depende de uma filosofia da historia e de uma psicologia humana. No que tange à filosofia da historia, Maquiavel a concebe como se fosse construlda por ciclos, por fatos que se repetem no tempo. O principe terá que ser suficientemente hábil para atar a experiência do passado à atualidade do presente, aprendendo a liçảo dos fatos acontecidos a fim de adaptálos às circunståncias e ser capaz de prever o futuro. Mas essa filosofia da história só se completa através da psicologia humana. O futuro soberano deve ter um conhecimento psicologico não só de si mesmo como também de quem o rodeia. Mediante essas duas disciplinas, ele será capaz de ter um comportamento eficiente, interierindo e mudando os rumos da historia de acordo com as suas caprichosas intençőes 5 .

Em Teoria do Medalháo, a aliança dessas duas disciplinas está sob a mira do autor-implicito. No caso da psicologia, alravés do adestramento do filho pelo pai que lhe rumina regras de comportamento; no caso da filosofia da história, na medida em que as expressōes filosóficas não devem levar à reflexão, mas à ostentação erudita: teoria e prática se soldam na manutençăo da aparência sem nenhuma inovação. A prática deve apenas confirmar a teoria já cristalizada pelo uso tradicional:

Filosofia da historia, por exemplo, é uma locuçảo que deves empregar com frequiencia, mas prolbo-te que chegues a outras conclu- 
E possivel destacar ainda dois pontos comuns entre o texto do pensador italiano $\theta$ o conto de Machado. O primeiro se refere à neutralidade moral do principe, a qual se manifesta quando o futuro governante sabe se adaptar à realidade vigente, tirando proveito de todas as situaçöes, sem tomar partido de nenhum lado. Essa neutralidade corresponde, no texto de Machado, à ausência de idélas, à capacidade de oscilar entre todas as opinióes sem ter nenhuma: "No entanto, podendo acontecer que, com a idade, venha a ser affigido de at gumas ideias proprias, urge aparelhar fortemente o espfrito." (p. 104)

O segundo ponto comum entre os dois textos a a capacidade de representaçăo. O príncipe, para Maquiavel, deve agir como um grande ator, oscilando entre o que é na realidade e o que aparenta ser; poltica e teatro dáo-se as mãos: "Confudo, o príncipe não precisa possuir todas as qualidades acima citadas, baslando que aparente possuf-las"16. (Grito meu)

Dessa forma, o diálogo entre pai e filho, em Machado, versando sobre o comportamento social da sociedade provinciana, semi-urbanizada, tenta espothar grotescameñte uma realidade polltica de nobreza européia, maquiavelicamente reforçando a ideologia do poder através da máscara social, que se equilibra entre as teorias do progresso, propostas pela ciência, e a prática polltica prudente do conservadorismo burguess.

\section{Representação e codificação do saber}

Por trás da espontaneidade"da representação social $\theta$ da banalidade desse ato, há no texto machadiano uma ironia mordaz contra o racionalismo burguês, já que fazer polttica é representar, sendo que esse processo, para ser eficiente, se apresenta como um saber codificado, como um adestramento mental. $E$ a ironia se estabelece na proporção em que representar bem o papel de medaIhão de forma precoce 6 ato de "gênio", 6 como um saber revelado a poucos $\theta$ que de tăo "diffcil" so é permitido a pessoas excepcionais que souberam precocemente fingir na sociedade: "Náo falo dos de vinte e cinco anos: esse madrugar é privilégio do gênio." (p. 103)

Essa "genialidade" 6 apresentada como um perfeito entendimento da "ciência ensinada": ciência da representação social, da hipocrisia burguesa. Ser medalhảo significa assim entrar num processo de aprendizagem esotérica da superficialidade, do corriqueiro e representar bem essa superficialidade $\dot{e}$ ato de "gênio": conciliação de contrários tecida muito bem pelo distanciamento do autor-implicito.

\section{Representação social e representação verbal: a retórica do vazio}

A retórica da representação, para ser coerente com a teoria do medalhăo, inibe o pensar. Se representar bem socialmente é colocado como um saber de "gênio", paradoxalmente esse saber implica em eliminar a reflexão. $O$ que importa é ostentar a erudiçăo: é nessa linha de raciocínio que, na ótica do pai, 6 
importanle visitar as livrarias "às escancaras", mas não ler livros. Da mesma forma, o uso da linguagem, ao invés de conduzir o raciocínio, deve apenas brilhar no salăo, ornamentar o torneado da frase no convivio social. Dal a simpatia do medalhão pelo adjetivo e nåo pelo substantivo: as palavras não devem conter idéias nucleares, mas apenas atributos. As frases feitas, as expressões gastas såo as mais freqüentes e quanto mais banais, mais eficazes, já que estảo na memória coletiva, nåo levando à reflexåo, mas ao uso mecânico:

Melhor do que tudo isso, porém, que afinal nåo passa de mero adorno, sấo as frases feitas, as locuçoes convencionais, as formulas consagradas pelos anos, incrustadas na memórla individual e pública. (p. 107)

Nessa retórica kitsch, apresentada pelo pai ao filho como um saber esotérico, ensinado a portas fechadas, a linguagem a ser usada pelo futuro medalhăo será destitulda do seu verdadeiro papel. A relaçăo entre significante e significado será bloqueada a serviço da mera ostentaçăo e da busca de poder. As palavras se tomarăo soltas do seu contexto, sujeitas ao preenchimento mesquinho das conveniancias sociais $\theta$ as intenç⿸尸es racionalistas do candidato a medaIhão. O efeito irónico resulta da lentativa de memorizar frases prontas, metáioras do bom-senso, frases estáticas em um código fluido por natureza. Essa retórica na verdade ostentará apenas o lado brilhante da medalha social, condenada à contemplaçăo do próprio umbigo de quem a usa, espelho das simulaçōes planejadas. E não é sem motivo que o pai aconselha ao futuro medalhão que escreva sua própria noticia, caso năo haja jornalistas que deveriam redigir o acontecimento, o banquete dado por ele: "Em lodo o caso, se as obrigaçóes desses cidadäos os retiverem noutra parte, podes ajudá-los de certa maneira, redigindo tu mesmo a noticia da festa." (p. 111)

A representação verbal, ensinada de pai para filho, construlda sob o prisma do autor-impllcito irônico, atinge seu auge no momento em que nåo se representa so para o outro, mas também para si mesmo, representação narcisica de um discurso de que se é emissor e recebedor, personagem e platêia ao mesmo temp.o. Eliminando-se qualquer tipo de reflexảo nessa forma de agir, evidentemente haverá uma simpatia pela chalaça e uma aversăo pela ironia. Enquanto portadora da vulgaridade, a chalaça, signo por excelencia da ostentaçăo, năo implica em distanciamento $\theta$ reflexåo. Os adjetivos atribuidos a ela (gorducha, redonda, franca) conotam lentidžo, obesidade, pouca sutileza, características típicas do medalhăo. Em oposiçăo, a ironia, que pede raciocinio, distanciamento e sutileza, 6 vista de forma altamente pejorativa, como uma doença, conotada sugestivamente pela palavra contraldo:

Somente náo deves empregar a ironia, esse movimento ao canto da boca, cheio de mistérios, inventado por algum grego da decadência, contraldo por Luciano, transmitido a Switt e Voltaire, feiçăo própria dos céticos e desabusados. (p. 114)

A narrativa vai sendo assim construlda nesses dois lados da medalha, nesse jogo de tensão entre o dilo e o omisso, entre a representaçăo social e a 
representaçăo verbal até atingir o ponto máximo na metalinguagem, quando o próprio discurso irônico se auto-espelha, remetendo-se à ironia como sendo desaconselhada, já que a sutil e silenciosa reflexão dela não se relaclona com a vulgar loquacidade da chalaça.

A ironia, enquanto fina reflexão, não se coaduna com a grosseria do medalhão. Da mesma forma, a sisudez aparente do figurão não tolera o humor, que relativiza os valores e desmascara esse mundo social: "Um grave pode ter seus momentos de expansåo alegre." (p. 114)

Rir só é permitido em determinadas circunstâncias. Riso medido, calculado, bem de acordo com a atmosfera "cientfica" da época, como afirma Flora Süssekind:

De fora do naturalismo, a lamina machadiana, cheia de ironia, torna-se mais afiada se pensamos na obsessiva busca de "seriedade" $e$ "objetividade" que marca a aliança da fiteratura brasileira com as clências naturais. Dal a profundidade do conte estético e ideológico operado por Machado de Assis na ficçâo naturalista com textos como "O Alienista" $\theta$ "Quincas Borba". E sobretudo com um humor que incomodava tanto a "seriedade" dos "estudiosos" naturalistas brasileiros. 17

A retórica do vazio, a nivel da linguagem, complementa assim o mundo da representação em dois niveis básicos da sociedade da época, a pollica e a ciência. Instaura-se, dessa forma, o discurso irônico, discurso apresentado como maquiavélico pelo autor-implicito, já que a linguagem, a ciência e a poltica simplesmente funcionam como meios para atingir os fins sempre mascarados dos medalhöes de provincia.

Nesse sistema allamente viciado só há um caminho: a ironia. Embora não resolva a situação contraditória vivida pelas elites, ela expőe essa contradiçăo e a ridiculariza através do silêncio de quem a constrói, relativiza os valores tidos como absolutos, desmascara esse discurso das simetrias. Expondo esse jogo mesquinho $\theta$ desvelando sutilmente essa representação maquiavélica do poder, ela acaba trazendo certa serenidade tanto para quem a elabora como para quem a percebe. Do seu canto ri o autor-implícito de modo distanciado, riso reticente, pois ele pode também, pelo leitor, tornar-se vfima da ironia, já que ela é faca de dois gumes. Do seu mundo de represenlação social ri $\theta$ ensina a rir racional e hipocritamente o medalhão. Ao filho, espera-se que ria, burguesamente, melhor do que o paj. Como já dizia o próprio Machado de Assis, "Cada um ri com a boca que tem."

\section{NOTAS}

1 ROMERO, Silvio. Machado de Assis. Rio de Janeiro, Jose Olympio, 1988, p. 80.

2 MURICY, Kátia. A razáo celica - Machado de Assis e as questóes de seu tempo. Rio de Janeiro. Companhia das Letras, 1988, p. 14.

3 ASSIS, Machado de. Teoria do Medalnăo. In: -. Papdis avulsos. Rlo de 'aneiro, W.M. Jackson Inc. Editores. 1955, p. 101-115.

4 RIEDEL. Dirce Cóntes. Metalora - o espelho em Machado de Assis. Rio de Janeiro, Livraria Francisco Alves Editora S/A, 1974, p. 95. 
5 ASSIS, Machado de. Memortas Postumas de Brás Cubas. Rio de Janeiro, Editora Tecnoprint, 1974, p. 19.

6 Ct. por exemplo: CYRANKA, Lúcla Furtado de Mendonça. A lronia como estrategia do co. - nhecimento e expressáo do literário. Dissertaça de Mestrado. Julz de Fora, Faculdade de Letras da UFJF (Convênio com a UFRJ), p. 11.

7 Cl.. Dor exemplo: MUECKE, D. C. The compass of irony, London, Methuen, 1969, p. 160.

$8 \mathrm{Ct}$, por exemplo: WARNING, Rainer. Le discours ironique et son lecteur. L'exemple de Flaubert. in: -. DALLENBACH, L et RICARDOU, J. (dir.). Problemes actuels de la lectura. Paris, Ed. Clancier - Guénaud, 1982, p. 123-125.

9 WARNING, Rainer, Op. cit. p. 125.

10 FERRAZ, Marla de Lourdes, A ironla romántica - estudo de um processo comunicalivo Lisboa, Imprensa Nacional/Casa da Moeda, 1987, p. 24-25:

11 MURICY, Kátia. Op. cit. p. 53.

12 SCHWARZ, Roberto. Que horas sáo? Rio de Janeiro, Companhia das Letras, 1987, p. 171.

$13 \mathrm{Ct}$, por exemplo: SUSSEKIND, Flora. Tal Brasil, qual romance? Rlo de Janeiro, Achiame, 1984, p. 40-59.

14 MURICY, Kátia. Op. cit p. 54

15 C., por exemplo: MARTINS, Cartos Estevam. introdugho. In: MAQUIAVEL, Nicolau. OPrincipe - Escritos Poltilicos - Trad. Livlo Xavier. Sto Paulo, Editora Abril Cultural, 1983, p. VIlXIX.

16 MAQÜIAVEL, Nicolau. Op. cit p. 74.

17 SUSSEKIND, Flora. Op. cit p. 136. 